Original Article

\title{
Incidence of floating toe and its association with the physique and foot morphology of Japanese children
}

\author{
Tomoko Araki, RPT, MScl, 2)*, Tadashi Masuda, PhD ${ }^{3)}$, Tetsuya Jinno, MD, $\mathrm{PhD}^{4}$, \\ SADAO Morita, MD, $\mathrm{PhD}^{2}$ \\ 1) Faculty of Rehabilitation, Kobe International University: 9-1-6 Koyocho-naka, Higashinada, Kobe, \\ Hyogo 658-0032, Japan \\ 2) Graduate School of Medical and Dental Sciences, Tokyo Medical and Dental University, Japan \\ 3) Faculty of Symbiotic Systems Science, Fukushima University, Japan \\ 4) Department of Joint Surgery and Sports Medicine, Graduate School of Medical and Dental Sciences, \\ Tokyo Medical and Dental University, Japan
}

\begin{abstract}
Purpose] Physical development, foot morphology, and toe contact of children aged 3 to 5 years were assessed in order to investigate the relationships between body and foot morphology and the incidence of the condition known as "floating toe". [Subjects] A total of 198 children, aged 3 to 5 years old, participated in this study. [Methods] Height and weight were measured for body morphology, and foot length and width were measured for foot morphology. Footprint images were taken to calculate the number of floating toes. Information about the children's height and weight at birth, and the time of starting to walk was obtained from their guardians. [Results] At least one floating toe was observed in $87.7-98.7 \%$ of the children depending on their ages. The fifth toe was most commonly affected, occurring in $74.2 \%$ of the study population. Among the body and foot morphology parameters, only weight at birth showed a significant but very weak correlation with the number of floating toes. [Conclusion] There was a high incidence of floating toe among the children, with the fifth toe most commonly affected. Floating toe weakly but significantly correlated with weight at birth, but did not correlated with other measures of physique at birth, physical development, or the time of starting to walk.

Key words: Foot morphology, Physical development, Floating toe
\end{abstract}

(This article was submitted Jun. 11, 2015, and was accepted Jul. 10, 2015)

\section{INTRODUCTION}

With its complex anatomical structure, the foot plays a vital role in supporting body weight, absorbing shock, and moving the body forward when walking ${ }^{1-3)}$. The toes also have the function of distributing load when walking ${ }^{4}$. The feet grow significantly during infancy ${ }^{5,6)}$ and have even been reported to develop before height ${ }^{7}$. Infancy is a period of remarkable physical development and is also an important period in terms of foot development ${ }^{5,8)}$.

In recent years, there have been occasional reports of "floating toe", a condition that does not involve pain or deformity in which the toes do not make contact with the ground when standing ${ }^{3)}$. In adults, the condition reportedly occurs as a result of surgery $\left.{ }^{9}, 10\right)$. Smith and Bernbach classified the condition into "floating toe" and "hammer toe"11), with the former caused by decreased flexor strength due to instability of the metatarsophalangeal joint. In adult cases of

*Corresponding author. Tomoko Araki (E-mail: araki@, kobe-kiu.ac.jp)

C2015 The Society of Physical Therapy Science. Published by IPEC Inc. This is an open-access article distributed under the terms of the Creative Commons Attribution Non-Commercial No Derivatives (by-ncnd) License $<$ http://creativecommons.org/licenses/by-nc-nd/3.0/>. floating toe, grip strength and ability to move forward are diminished $^{12)}$.

The onset age of floating toe remains unclear. Although there have been no studies reported in English, a study of Japanese children reported a high incidence of this condition $^{13)}$. This incidence increased in the 2000s than in the $1980 \mathrm{~s}^{14)}$ and is suggested to be affected by how much a child plays outdoors.

The purpose of this study was to investigate the incidence of the condition known as "floating toe" and its relationships between body and foot morphology of Japanese children aged 3 to 5 years.

\section{SUBJECTS AND METHODS}

The subjects were 198 Japanese children (102 boys and 96 girls) aged 3 to 5 years (Table 1). Enrollment criteria were no morphological deformities of the feet and no past medical history of the feet. Children with neurological or orthopedic disorders affecting foot morphology were excluded. The children all attended the same kindergarten, and the measurements were performed in the same environment.

Before commencing the measurements, the nature and methods of the study were fully explained to the children and their guardians, and verbal consent from the children and written consent from their guardians were obtained, in- 
Table 1. The number of the subjects and their physical characteristics

\begin{tabular}{lcccccc}
\hline Age & Total & Boys & Girls & Month age $(\mathrm{yrs})$ & Height $(\mathrm{cm})$ & Weight $(\mathrm{kg})$ \\
\hline$(\mathrm{yr})$ & $(\mathrm{N})$ & $(\mathrm{N})$ & $(\mathrm{N})$ & $(\mathrm{M}$, mean \pm SD $)$ & $(\mathrm{cm}$, mean $\pm \mathrm{SD})$ & $(\mathrm{kg}$, mean $\pm \mathrm{SD})$ \\
\hline 3 & 57 & 30 & 27 & $41.6 \pm 2.3$ & $95.8 \pm 3.9$ & $14.4 \pm 1.5$ \\
4 & 62 & 32 & 30 & $54.3 \pm 3.2$ & $102.9 \pm 4.3$ & $16.9 \pm 2.1$ \\
5 & 79 & 40 & 39 & $65.6 \pm 3.6$ & $108.8 \pm 4.7$ & $18.4 \pm 3.0$ \\
Total & 198 & 102 & 96 & $55.1 \pm 10.3$ & $103.2 \pm 6.8$ & $16.7 \pm 2.9$ \\
\hline
\end{tabular}

dicating their willingness to participate in the study. In order to mitigate the burden of repeated measurements, children were able to withdraw from the study part way through. The study was conducted with the prior approval of the Ethics Committee of Saitama Prefectural University.

Physical characteristics and foot morphology were measured, footprint images were taken, and a questionnaire was administered. All measurements were conducted between 8:00 and 10:00 a.m. to minimize the effect of circadian variation. Moreover, one tester conducted all measurements to eliminate inter-observer error.

The physical characteristics measured were height and weight. For foot morphology, foot length and width were measured using a sliding scale (Junior Brannock Device, The Brannock Device Inc., NY, USA). Foot length was measured as the distance from the second toe to the center of the heel, and foot width was measured as the straight line from the first MTP joint to the head of the fifth metatarsal orthogonal to foot length. Measurements were performed with the subjects in the standing position.

Footprint images were taken using an ink foot printer (Pedoprint foot imprinter set, Bauerfeind Co., Ltd., Thüringen, Germany). The foot imprinter consists of a rubber mat with a net underneath that is impregnated with ink. A piece of paper is placed beneath the net, and a footprint impression is made by having the subject stand on the rubber mat. Good images were not obtained for several of the 3-year-old children when standing, so they were verbally instructed to sit with their feet on the rubber mat and then to stand up still while looking at a point 2 meters ahead for 5 seconds until a good image was obtained. Footprint images were taken of both feet. Assessment of toe contact was done based on these footprint images. Toe contact was assessed as 1 point if a toe imprint was even slightly visible and 0 points if there was absolutely no visible toe imprint. Total scores were calculated for the left and right feet and then analyzed as the number of toes in contact with the ground. The number of floating toes was determined from the data of contacting and non-contacting toes, and the results were analyzed.

The questionnaire asked the children's guardians about their child's developmental history, height and weight at birth, and when he/she started walking without assistance.

In the statistical analysis, Spearman's rank correlation coefficient was calculated using age in months, physique, foot morphology, and toe contact as variables. Partial correlation was also assessed using age in months, height and weight as moderator variables. Statistical analyses were performed using SPSS Statistics 20 (IBM Co., Ltd., IL, USA), and significance was accepted for values of $\mathrm{p}<0.05$.

\section{RESULTS}

Age in months, height, weight, and foot length and width all exhibited significant correlations $(\mathrm{p}<0.01)$. Among the physical attributes, height had a particularly strong correlation with foot length and width. There were no significant correlations between the number of the floating toe and the height or weight of the children at the time of measurement. Only foot length significantly correlated with height and weight at birth. However, the absolute value of the correlation coefficient was 0.152 , so even though it was significant, the correlation was very weak $(\mathrm{p}<0.05)$. There were no differences by gender in all these results.

At least 1 floating toe was observed in over $87 \%$ of all children: $87.7 \%$ of the 3 -year-old children (50 children), $88.7 \%$ of the 4 -year-old children ( 55 children), and $98.7 \%$ of the 5-year-old children ( 78 children). The majority of children had either 0 or 1 floating toe on both the left and right foot at all ages (3-year-old: left $52.7 \%$, right $59.7 \%$; 4-year-old: left $62.9 \%$, right $56.4 \%$; 5-year-old: left $69.6 \%$, right $60.7 \%$ ) (Table 2). The most common total number of floating toes on both feet was 2, occurring in $26.3 \%, 24.2 \%$, and $25.3 \%$ of the 3,4 , and 5 -year-old children, respectively. The fifth toe was the most common floating toe, occurring in $74.2 \%$ of children of all ages (Table 3 ).

Partial correlation using age in months, height, and weight as the modulator variables revealed that only weight at birth was significantly correlated with the number of floating toes on both feet $(p<0.05)$. The absolute value of the partial correlation coefficient was 0.147 , showing a very weak correlation. There were no significant correlations for the other partial correlation variables of height at birth, time of starting to walk, and foot length and width (Table 4).

\section{DISCUSSION}

There were strong correlations between foot morphology and child age in months, height, and weight, with a particularly strong correlation for height. This finding suggests that foot morphology growth is related more closely to height than to age in months and weight. Weight at birth exhibited a weak but significant correlation with floating toe. Height at birth was not related to foot morphology or floating toes.

In terms of foot contact, we found that floating toe was present in the majority of subjects and most frequently involved the fifth toe. Also in a study of 300 children aged 3 to 5 years reported in Japanese by Matsuda et al. ${ }^{15}$ ), a high incidence of floating toe was also seen in all age groups, but the incidence of floating toe in toes other than the fifth 
Table 2-1. Incidence rates of "floating toes" on one foot

\begin{tabular}{ccccccccccccc}
\hline & Left (\%) & \multicolumn{10}{c}{ Right (\%) } \\
\hline & 0 & 1 & 2 & 3 & 4 & 5 & 0 & 1 & 2 & 3 & 4 & 5 \\
\hline $3 \mathrm{Y}$ & 31.6 & 21.1 & 15.8 & 15.8 & 15.8 & 0.0 & 28.1 & 31.6 & 28.1 & 5.2 & 7.0 & 0.0 \\
$4 \mathrm{Y}$ & 24.2 & 38.7 & 19.4 & 8.0 & 8.0 & 1.6 & 29.0 & 27.4 & 24.2 & 11.3 & 8.0 & 0.0 \\
$5 \mathrm{Y}$ & 21.5 & 48.1 & 21.5 & 1.2 & 6.3 & 1.2 & 10.1 & 50.6 & 21.5 & 10.1 & 2.5 & 5.2 \\
\hline
\end{tabular}

Table 2-2. Incidence rates of "floating toes" on both feet (\%)

\begin{tabular}{cccccccccccc}
\hline & 0 & 1 & 2 & 3 & 4 & 5 & 6 & 7 & 8 & 9 & 10 \\
\hline $3 \mathrm{Y}$ & 12.3 & 12.3 & 26.3 & 12.3 & 12.3 & 12.3 & 7.0 & 1.8 & 3.5 & 0.0 & 0.0 \\
$4 \mathrm{Y}$ & 11.3 & 14.5 & 24.2 & 19.4 & 14.5 & 4.8 & 3.2 & 4.8 & 1.6 & 1.6 & 0.0 \\
$5 \mathrm{Y}$ & 1.3 & 25.3 & 25.3 & 12.7 & 16.5 & 11.4 & 5.1 & 0.0 & 0.0 & 1.3 & 1.3 \\
\hline
\end{tabular}

Table 3. Percentage occurrence of "the floating toes" in each age group

\begin{tabular}{|c|c|c|c|c|c|c|}
\hline & & $\begin{array}{l}\text { First } \\
\text { toe }\end{array}$ & $\begin{array}{l}\text { Second } \\
\text { toe }\end{array}$ & $\begin{array}{l}\text { Third } \\
\text { toe }\end{array}$ & $\begin{array}{c}\text { Fourth } \\
\text { toe }\end{array}$ & $\begin{array}{c}\text { Fifth } \\
\text { toe }\end{array}$ \\
\hline \multirow{2}{*}{$3 \mathrm{Y}$} & Right & 0.0 & 8.7 & 17.5 & 38.5 & 66.6 \\
\hline & Left & 0.0 & 22.8 & 28.0 & 43.8 & 68.4 \\
\hline \multirow{2}{*}{$4 \mathrm{Y}$} & Right & 0.0 & 16.1 & 20.9 & 32.2 & 59.6 \\
\hline & Left & 1.6 & 9.6 & 12.9 & 33.8 & 72.5 \\
\hline \multirow{2}{*}{$5 \mathrm{Y}$} & Right & 3.7 & 7.5 & 16.4 & 36.7 & 88.6 \\
\hline & Left & 1.2 & 10.1 & 8.8 & 29.1 & 75.9 \\
\hline \multicolumn{2}{|c|}{ Total (\%) } & 2.7 & 13.6 & 17.1 & 36.8 & 74.2 \\
\hline
\end{tabular}

toe decreased with age according to their longitudinal observation. A decreasing number of floating toes with age was not found in the present study, which was based on a cross-sectional study design.

The present results also indicate that the number of floating toes is not related to foot morphology, height at birth, or time of starting to walk. Foot morphology strongly correlated with both age in months and height, but our present findings suggest that floating toe occurs regardless of age in months, height, foot morphology, or time of starting to walk. Weight at birth had a very weak correlation with the number of floating toes of both feet, but this tendency was not seen for the left or right foot alone, precluding a strong assertion that weight at birth affects floating toe. These findings suggest that floating toe does not occur with increased age or physical development, but is affected by other factors, such as motor development or environmental or lifestyle factors.

In terms of motor development, it has been reported that standing balance control of children aged 6 years and older undergoes a transition to become almost the same as that of adults ${ }^{16,17)}$. A separate study argued that, in terms of the standing balance control of children aged 6 years and younger, inputs from the support surface and the muscles surrounding the ankles play an important role in dynamic balance control. When these inputs are inadequate, visual inputs tend to be incorrect, making balance maintenance difficult even when there is correct input to the vestibular system and motor senses other than ankles ${ }^{18)}$. These findings
Table 4. Partial correlation coefficient between the physical morphology and "the floating toe"

\begin{tabular}{lccc}
\hline \multirow{2}{*}{ Evaluation item } & \multicolumn{3}{c}{ the floating toe } \\
\cline { 2 - 4 } & Right & Left & Both \\
\hline Foot length & & & \\
$\quad$ Right & -0.080 & 0.103 & 0.018 \\
$\quad$ Left & -0.110 & 0.013 & -0.061 \\
Foot width & & & \\
$\quad$ Right & 0.047 & 0.120 & -0.104 \\
$\quad$ Left & 0.010 & 0.070 & 0.051 \\
Height at birth & 0.082 & 0.085 & 0.103 \\
Weight at birth & 0.110 & 0.130 & $0.147^{*}$ \\
Time of starting to walk & 0.009 & 0.036 & 0.028 \\
\hline
\end{tabular}

$* \mathrm{p}<0.05$

indicate that understanding foot contact from infancy and continuing to observe a subject throughout his/her physical and motor development are essential to help ensure proper balance control and gait. A study of plantar pressure in children aged 3.5 to 6.5 years by Matsuda and Demura ${ }^{19)}$ found that, during infancy, plantar pressure on the front of the foot increases, and individual differences decrease as children get older, while Kojima and Takemori ${ }^{20)}$ found in a study of individuals aged 1.5 to 20 years, that pressure in the center of the foot tends to move forward with age. Taken together with the present finding that floating toe is not related to age in months or physical development, these results indicate the necessity of considering foot development from several points of view such as plantar pressure, motor development, and lifestyle factors.

\section{REFERENCES}

1) Scott AT, Hendry TM, Iaquinto JM, et al.: Plantar pressure analysis in cadaver feet after bony procedures commonly used in the treatment of stageIIposterior tibial tendon insufficiency. Foot Ankle Int, 2007, 28: 1143-1153. [CrossRef]

2) Chou SW, Cheng HY, Chen JH, et al.: The role of the great toe in balance performance. J Orthop Res, 2009, 27: 549-554. [Medline] [CrossRef]

3) Fukuyama K, Maruyama H: Occurrence of floating toe from the viewpoint of the structure of foot arch. J Phys Ther Sci, 2011, 23: 33-36. [CrossRef]

4) Hughes J, Clark P, Klenerman L: The importance of the toes in walking. J 
Bone Joint Surg Br, 1990, 72: 245-251. [Medline]

5) Anderson M, Blais M, Green WT: Growth of the normal foot during childhood and adolescence; length of the foot and interrelations of foot, stature, and lower extremity as seen in serial records of children between 1-18 years of age. Am J Phys Anthropol, 1956, 14: 287-308. [Medline] [CrossRef]

6) Gould N, Moreland M, Trevino S, et al.: Foot growth in children age one to five years. Foot Ankle, 1990, 10: 211-213. [Medline] [CrossRef]

7) Cheng JC, Leung SS, Leung AK, et al.: Change of foot size with weightbearing. A study of 2829 children 3 to 18 years of age. Clin Orthop Relat Res, 1997, (342): 123-131. [Medline]

8) Bosch K, Gerss J, Rosenbaum D: Development of healthy children's feetnine-year results of a longitudinal investigation of plantar loading patterns. Gait Posture, 2010, 32: 564-571. [Medline] [CrossRef]

9) Hofstaetter SG, Hofstaetter JG, Petroutsas JA, et al.: The Weil osteotomy a seven-year follow-up. J Bone Joint Surg Br, 2005, 87: 1507-1511. [Medline] [CrossRef]

10) Migues A, Slullitel G, Bilbao F, et al.: Floating-toe deformity as a complication of the Weil osteotomy. Foot Ankle Int, 2004, 25: 609-613. [Medline]

11) Smith FT, Bernbach M: Iatrogenic metatarsus elevatus, floating toes general considerations. http://www.podiatryinstitute.com/pdfs/Up date 1987/1987 28.pdf(Accessed Oct. 1, 2014)
12) Fukuyama $\mathrm{K}$, Osanai $\mathrm{M}$, Maruyama $\mathrm{H}$ : Adult toe contact and the function of floating toes. Rigakuryouho Kagaku, 2009, 24: 683-687. [CrossRef]

13) Uchida T, Fujiwara K, Sasaki K, et al.: Measurement of foot configuration of kindergarten children. Kutsuno Igaku, 2003, 16: 96-99.

14) Harada S: A study on physical structures of preschool children's feet compared between 1980 and 2000. Kutsuno Igaku, 2002, 15: 14-18.

15) Matsuda S, Demura S, Kasuga K: Changes in floating-toes one year later in preschool children based on longitudinal data. Jpn J Hum Growth Dev Res, 2011, 51: 19-26. [CrossRef]

16) Assaiante C, Amblard B: An ontogenetic model for the sensorimotor organization of balance control in humans. Hum Mov Sci, 1995, 14: 13-43. [CrossRef]

17) Rival C, Ceyte H, Olivier I: Developmental changes of static standing balance in children. Neurosci Lett, 2005, 376: 133-136. [Medline] [CrossRef]

18) Forssberg H, Nashner LM: Ontogenetic development of postural control in man: adaptation to altered support and visual conditions during stance. J Neurosci, 1982, 2: 545-552. [Medline]

19) Matsuda S, Demura S: Age-related, interindividual, and right/left differences in anterior-posterior foot pressure ratio in preschool children. J Physiol Anthropol, 2013, 32: 8. [Medline] [CrossRef]

20) Kojima S, Takemori S: Development of body balance in children. Pract Otorhinolaryngl, 1980, 73: 865-871. 